\title{
Developing Digital Intervention Games for Mental Disorders: A Review
}

\author{
Avani Shah, PhD, MSW, Kyle R. Kraemer, MA,2 Cho Rong Won, BSW, \\ Sheila Black, $\mathrm{PhD}^{2}$, and Will Hasenbein, $\mathrm{MA}^{1}$
}

\begin{abstract}
There is limited research on mental health interventions delivered in a digital game format and even less to guide developers on how to develop such games. This review focuses on understanding how to develop therapeutic digital games based primarily on mental health intervention games that have been empirically tested. The review was generated through database searches and backward search techniques for digital gamebased interventions for specific mental disorders. We evaluated digital games that were based on validated psychological treatments. We located 24 studies and 18 games that met our search criteria. These games and their outcomes have been summarized. This review showed that these types of games have the potential to make an impact on mental health concerns but that there are currently few digital games available for the treatment or prevention of mental disorders. In addition, guidelines for digital mental health intervention game development have been presented. The consolidation of guidelines addressing multiple game development factors (e.g., time, cost, engagement) may help those interested in developing new therapeutic games that target a greater variety of disorders, thereby expanding access to larger populations.
\end{abstract}

Keywords: Review, Guidelines, Game development, Serious game, Mental health, Videogame

\section{Introduction}

D IGITAL GAMES HAVE gained mainstream appeal with the widespread availability of delivery platforms: computers, iPads, tablets, and smartphone gaming apps. ${ }^{1}$ The videogame (VG) industry reports 150 million American users, with $44 \%$ being female and $27 \%$ being aged 50 or older. ${ }^{2}$ Gamers play for the competition among friends, stress relief, and the challenge. ${ }^{3}$ The research focus on the negative impact of gaming ${ }^{4}$ (e.g., VG addiction in massive multiplayer online role playing games [MMORPGs], aggression in violent VGs such as first person shooter) has shifted to the positive impact of VGs over time. ${ }^{1}$ Research points to cognitive, social, motivational, and emotional mechanisms through which gaming can be beneficial, ${ }^{5}$ contributing to a renewed interest in VGs as potential therapeutic games (TGs).

Research has emerged as TGs have become available. ${ }^{6}$ Many play VGs specifically for the purpose of mood repair/enhancement ${ }^{7}$ and certain commercial VGs may have the potential for mood repair. ${ }^{8}$ Some practitioners have investigated the usefulness of commercial games or "casual games" for mental health intervention, such as "Lock-On: Modern Air Combat" 8 for mood, "Tetris" 9,10 for decreasing traumatic flashbacks, "The Sims Life Stories", to engage adolescents in emotion regulation, "Left 4 Dead" ( $\beta 2008$ Valve, USA) ${ }^{12}$ for stress management, exergames (e.g., Nintendo ${ }^{\circledR}$ $\left.\mathrm{Wii}^{\mathrm{TM}}\right)^{13-15}$ for depression and attention deficit and hyperactivity disorder (ADHD), or MMORPGs (e.g., "World of Warcraft" $)^{16-18}$ for depressive symptoms. Even simple puzzle games such as "Bookworm Adventure," "Peggle," and "Bejeweled" lead to improved mood and anxiety on self-report measures. ${ }^{19,20}$

Granic et al. ${ }^{5}$ identify game types, reflecting the potential variety of games useful for mental health treatment. Depending on the skill and audience, games can be created on a continuum of complexity and social interaction. TGs can vary from simple puzzle-type games to more complex games involving additional components: fantasy, story genre, immersion into the game, level of interactivity, and story line development. ${ }^{5}$ Recent trends involve the creation and

\footnotetext{
${ }^{1}$ School of Social Work, University of Alabama, Tuscaloosa, Alabama.

${ }^{2}$ Department of Psychology, University of Alabama, Tuscaloosa, Alabama.
} 
evaluation of "serious games" with a psychoeducational component designed to improve particular mental conditions. ${ }^{21}$

Serious games that are specifically designed as interventions or supplements to treatment have been delivered to people undergoing cognitive behavioral therapy (CBT), ${ }^{22}$ and experiencing depression, anxiety, stress, eating disorders, autism, driving phobia, or other conditions. ${ }^{13,23-30}$ Previously, VGs enhanced a relationship between therapists and adolescents. ${ }^{31}$

\section{Methods}

\section{Search strategies}

As the digital mental health intervention field is still in its infancy, we sought to review the literature on digital games based on validated traditional psychological interventions for mental disorders to generate a set of guidelines to aid game developers. Our search strategy is detailed in Figure 1, a flow diagram. In addition to database searches of articles published until December 2017, we examined the references of relevant review articles $(n=43)$ and conducted Google searches. During database searches, the title and abstract were screened for eligibility. If the article could not be included or excluded based on this information, the full article was obtained and reviewed for inclusion. Two researchers reached a consensus on each study to determine inclusion.

\section{Selection process}

Inclusion criteria. We included articles that were (1) peer reviewed and (2) in the English language. The studies must have been empirical with a pre/postintervention statistical outcome on a psychological self-report measure. We included any digital game interventions (computer, mobile, tablet, Internet) developed for the purpose of intervening with a specific mental disorder.

Exclusion criteria. We excluded commercial videogames such as MMORPGs because we were more interested in games developed specifically for mental health diagnoses rather than for entertainment purposes. Likewise, exergames, many of which were commercially designed for the purpose of improving physical functioning and not on validated psychological interventions (see Li et al. ${ }^{32}$ ), were excluded. We chose to exclude virtual reality (VR) games as they have a unique and complex game development process that is reviewed elsewhere. $^{33}$

Also, we excluded cognitive rehabilitation, educational, and social skills games because we were more interested in studying games targeting emotion management as opposed to cognitive processes such as executive functioning, attention, processing speed, memory, social cognition, language, or solely learning content. We also chose to exclude case studies.

\section{Results}

Over 100 studies were found (Fig. 1). Of these studies, $N=24$ were included and $N=18$ games located. See Table 1 for a summary of the studies.

Many of the currently reviewed TGs are based on biofeedback, CBT, and stimulus control for treating depression, anxiety, anger, ADHD, bulimia nervosa, and substance use. Certain mental disorders may be underrepresented in this review due to exclusions of cognitive rehabilitation (CR), educational/social skills, and VR games. Many of the CR or educational games target disorders such as autism ${ }^{34,35}$ (see game development reviews ${ }^{36,37}$ ), ADHD, dementia/neurocognitive impairment, schizophrenia, ${ }^{38}$ and depression. ${ }^{39}$ Similarly, VR games tended to treat anxiety disorders. ${ }^{40,41}$

In other cases, we excluded games based on their descriptions. For example, "Think Feel Do," 42 noted in one TG review, ${ }^{43}$ is attractive to children but the developers did not describe it as a game. The following is a brief discussion of the games and studies included in the review followed by game development guidelines based on these games.

\section{Current games for mental disorders}

Depression and mood. TGs have been developed to aid mood disorders and related conditions. 44 "SPARX," a CBT game designed for adolescents with clinical depression, significantly improved depression, anxiety, and hopelessness with better remission rates than treatment as usual (TAU). ${ }^{45-48}$ "Rainbow SPARX" is a variant designed for diverse sexual orientations. " "SPARX" is a seven-level fantasy game with the goal of restoring balance by addressing the negative thoughts affecting the fantasy world. Another CBT fantasy game designed for adolescents with depressive symptoms is "The Journey," 49 in which players travel through seven themed modules, earning points on completing each module. Rewards are simple mini-games. Compared to the attentional placebo, the intervention group had greater improvements in depression.

Unsurprisingly, many TGs, including those targeting depression, have focused on treatment for children. Several games that have been effective for depression use biofeedback. With this operant conditioning approach, the players' physiology (heart rate, breathing, brain activity, and/or skin conductance measured through sensors attached to their body) controls or alters the gameplay. For example, ${ }^{23}$ the biofeedback games "Freeze-Framer" and "Journey to the Wild Divine" are controlled by heart rate and skin conductance levels, which are monitored by sensors attached to the players' fingers.

In "Journey to the Wild Divine," players engage in meditation and breathing techniques to maintain lower physiological arousal levels, which manipulate music, imagery, and game goals such as building a fire, building a bridge, or shooting a bow and arrow. "Fo "Freeze Framer" uses arousal levels to guide the activity of coloring a meadow or maneuvering a floating hot air balloon through a landscape. ${ }^{23}$ These games significantly lowered posttest depression scores in the intervention group when compared with a control group.

Addiction and impulse control. TGs have been developed for controlling impulses in alcoholism, bulimia nervosa, and gambling disorder.

One intervention for treating alcoholism in military populations is the game "Guardian Angel.",24 Functioning as an in-game practice environment, players hone skills such as managing cravings with feedback from a cravings meter, drink refusal in social settings, temptation avoidance through a driving-route planner, and individual resource development through "Go to therapy." The player selects each of these through a series of mini-games. "Clean House," a stimulus control mini-game, encourages the player to find and remove all alcohol-related items within 4 minutes. While players using the game showed lower scores on the Obsessive Compulsive 
Search terms used:

computer games OR video games OR serious games OR digital games OR games

AND

mood OR depression OR anxiety OR stress OR mental health OR mental disorder OR psychotherapy

Databases used for EBSCO Search:

Academic Search Premier, PsycINFO, and Medline

Inclusion criteria:

Empirical, digital game intervention developed for mental disorder, self-reported mental health outcome (pre/post), English language, peer-reviewed

Exclusion criteria:

Virtual reality, educational/social skills game, cognitive rehabilitation game, commercially available casual video game/MMORPGs, exergame, case studies

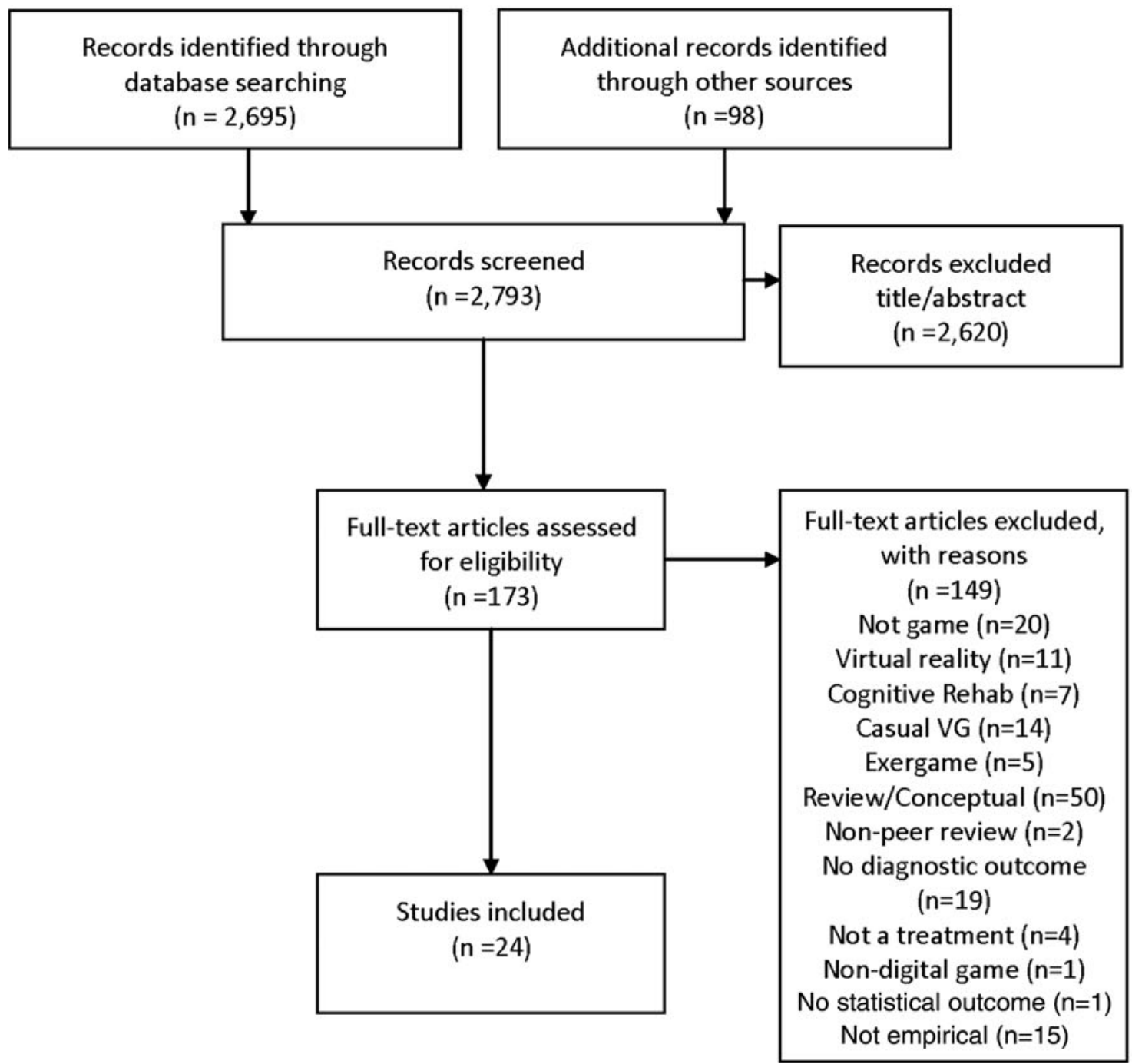

FIG. 1. Flowchart of inclusion/exclusion criteria and included/excluded studies. 


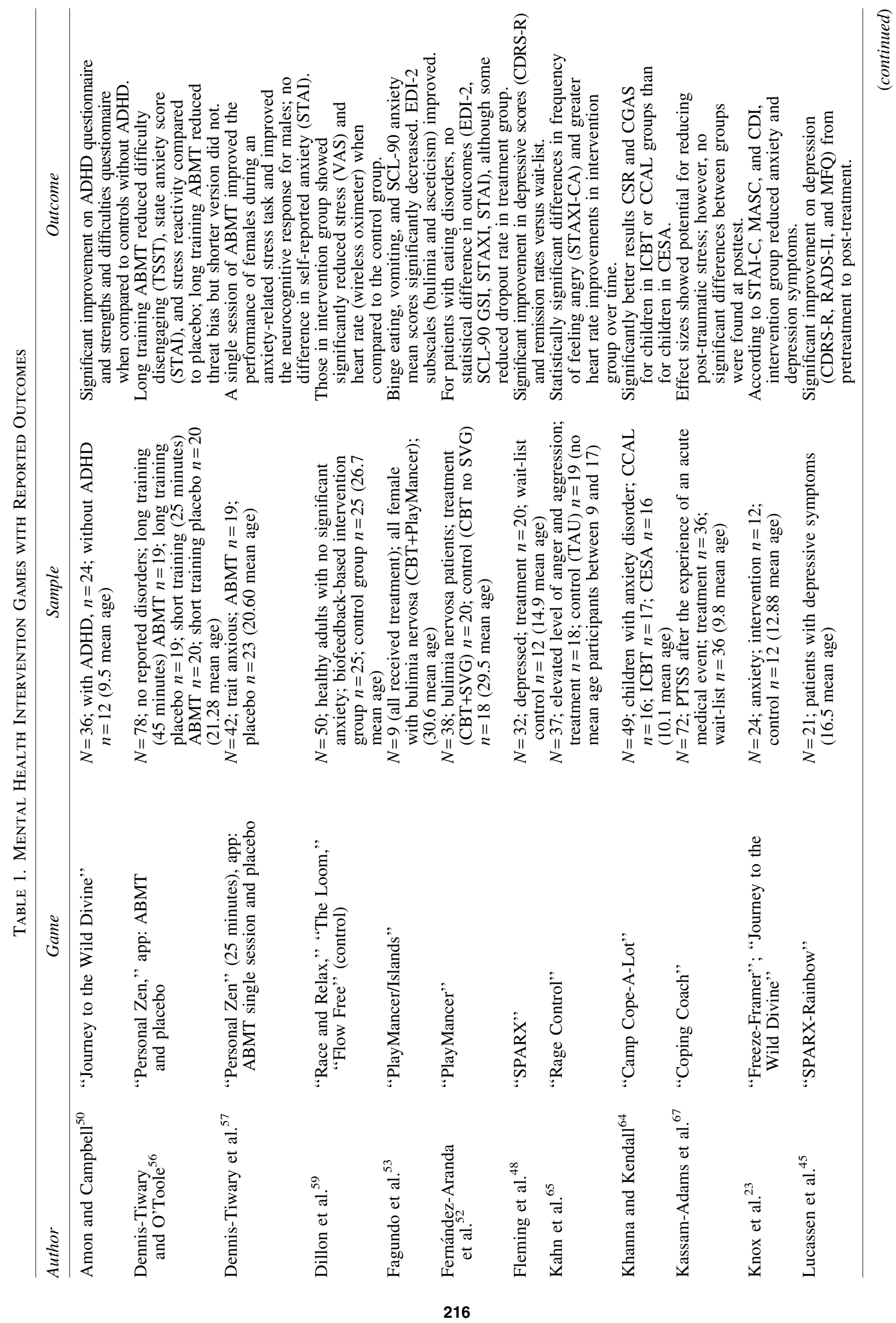




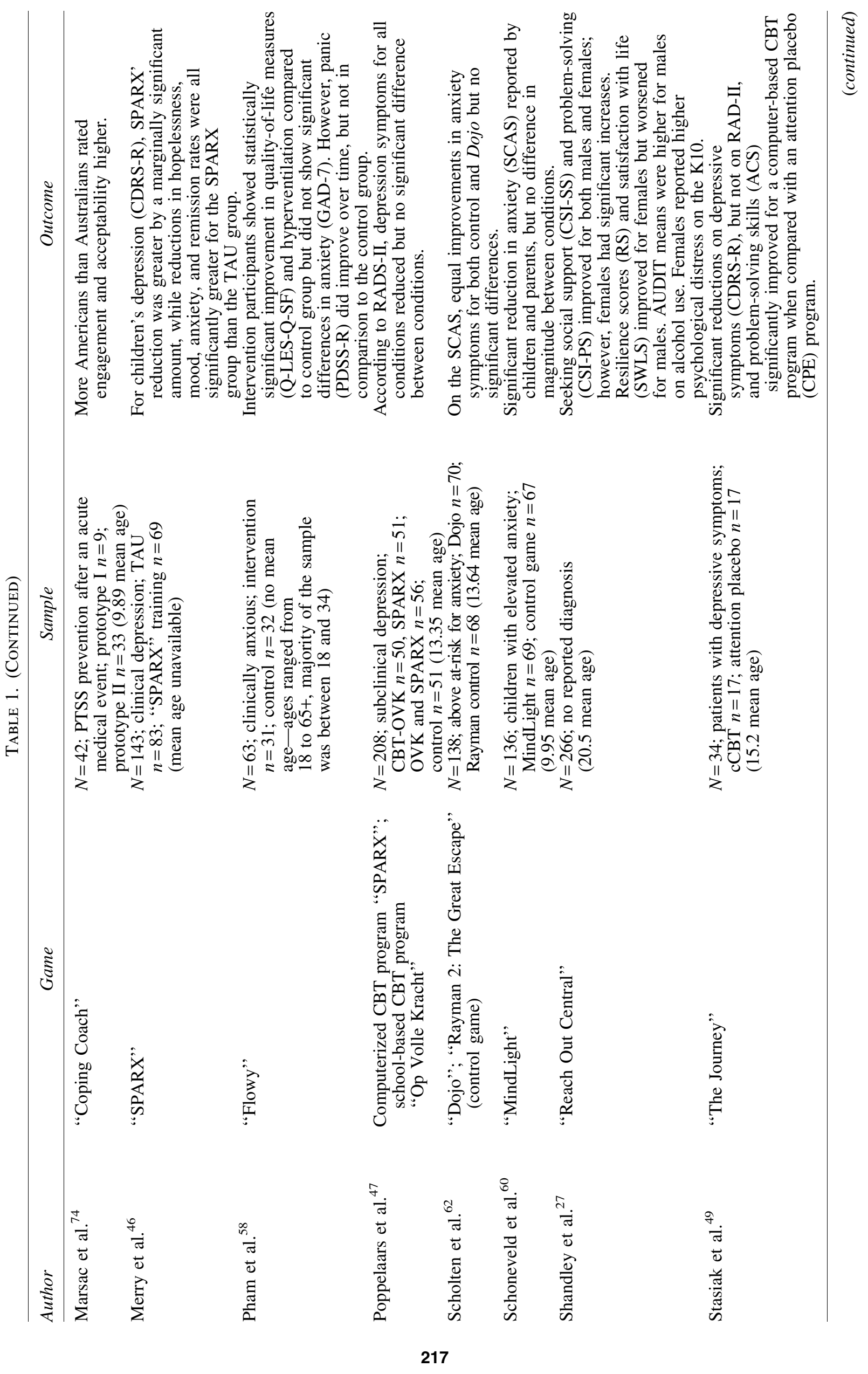




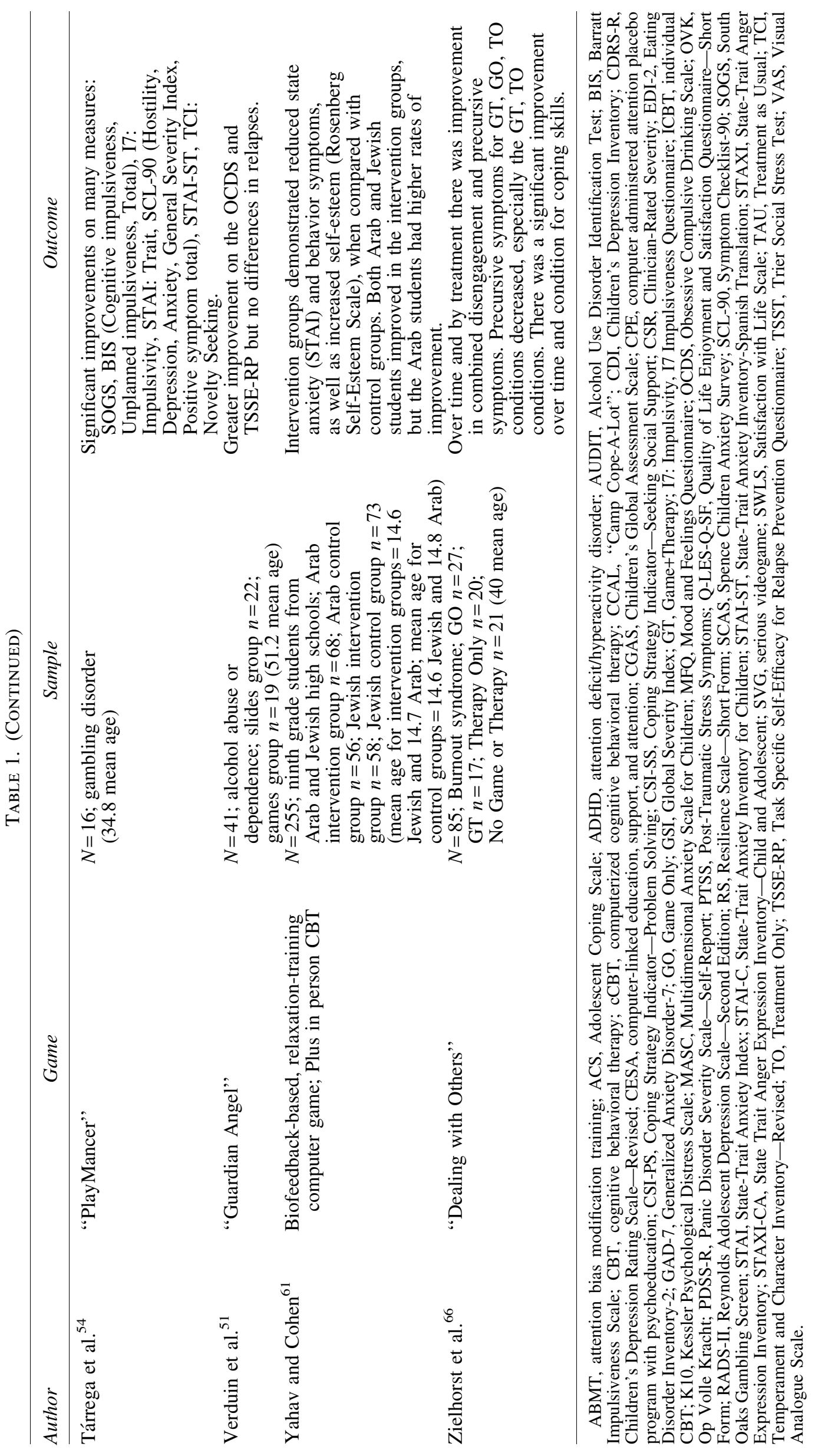


Drinking Scale (OCDS) and higher self-efficacy, relapse rates did not differ between game players and a control group who viewed educational slides. ${ }^{51}$

Researchers have also tested the effect of "Reach Out Central" on alcohol consumption. ${ }^{27}$ The game involves playing a character who must navigate the challenges of being new in town. "Reach Out Central" helps younger adults identify and develop practical stress coping skills. While improvements occurred in areas such as problemsolving, seeking support, and resilience, researchers did not find significant differences in alcohol consumption across time.

Similarly, "PlayMancer," a biofeedback game, was developed to treat impulse-related disorders. ${ }^{25,52}$ Physiological responses (heart rate, galvanic skin response, breathing frequency) determine obstacles and difficulty level as players tackle mini-games targeting problem-solving, impulse control, confrontation of frustrating situations, and negative emotion management.

When tested as a supplement to CBT for bulimia nervosa, use of "PlayMancer/Islands" led to improved emotion regulation and decreased impulsivity. ${ }^{53}$ This consisted of three minigames: "Face of Cronos" (obstacles appear based on arousal while climbing a cliff), "Treasures of the Sea" (collecting fish and artifacts while swimming and maintaining oxygen based on arousal), and "Sign of Magupta" (connecting stars in constellations based on breathing control). "PlayMancer" has also been used as an adjunct for CBT for gambling disorder with positive outcomes on a gambling self-report measure, the Symptom Check List-90, and subscales of an impulsivity and anxiety assessment. ${ }^{54}$

Anxiety and stress. People use games for recovery to disengage from work, relax, and gain mastery and control. ${ }^{55}$ "Personal Zen," a game version of attentional bias modification, which implicitly trains participants to attend away from negative stimuli (in this case, angry faces), has significantly reduced state anxiety and stress reactivity. ${ }^{56}$ The goal of this game was to trace the trail left by one of two sprites (the nonthreatening one) after both burrow into the grass. Different colored jewels are awarded depending on response speed and accuracy. Delivery as an app on a mobile device makes it highly accessible. A second study using this game ${ }^{57}$ for 25 minutes (vs. 45 minutes in the previous study) found improved performance during a stressor for some but no changes in selfreported anxiety, suggesting the importance of length of play.

Another mobile app, "Flowy," 58 is a breath-retraining game developed specifically for anxiety, panic attacks, and hyperventilation management. The game is operated (e.g., a sailboat moves down river or balloons fly into the sky through a series of mini-games and levels) where players press the mobile phone screen when inhaling and let go when exhaling. Perhaps attaching a breath-monitoring device to the phone would improve panic and hyperventilation overtime as these were not significantly different from the waiting list group.

"Loom" and "Relax and Race," mobile phone game applications that used an electrodermal sensor to monitor skin conductance and heart rates, found significantly improved levels of stress and heart rate when compared with the control group "Free Flow." 59

"MindLight," a neurofeedback, CBT, and attentional bias modification training (ABMT)-based game approach, resulted in improvements in anxiety over time but not when compared with "Max and the Magic Marker." 60 In "MindLight," players use a one-channel dry sensor headset that converts EEG waves into the amount of light coming from the avatar's headset. Players create more or less light based on how relaxed they are navigating a dark haunted mansion and overcoming anxiety-inducing experiences to rescue the grandmother. The ABMT component encourages children to attend to the smiling faces over the negative faces.

Other biofeedback games, "Journey to the Wild Divine" and "Freeze-Framer," lead to significantly lower self-report and trait anxiety scores compared to the waiting list group. ${ }^{23}$ Improvements in state anxiety and self-esteem have also been noted with a combination intervention: in-person CBT plus a biofeedback game that used two electrodes on the fingers to measure electrodermal activity. ${ }^{61}$ Limited information was provided about this game.

Another game using biofeedback, "Dojo," found that improvements in anxiety were not greater than those made by playing a non-TG, "Rayman 2"; the researchers did find, however, a steeper decline in personalized anxiety symptoms for adolescents who played "Dojo" rather than "Rayman 2." ${ }^{62}$ In "Dojo," after initial training in deep-breathing, progressive muscle relaxation, positive thinking, and guided imagery, the player engages in emotion-inciting puzzles that increase in difficulty based on heart rate variability monitored via sensors attached to the player's fingers. ${ }^{63}$

Other anxiety and anger management games have relied on CBT as the primary change mechanism. "Camp Cope A Lot," 64 a multicomponent CBT game (relaxation, VGs, exposure) delivered with the therapist and at times the parent, resulted in improvements in anxiety. "Rage Control,", 65 with gameplay elements similar to the classic arcade game "Space Invaders," relies on heart rate arousal levels via sensors on the players' fingers to help children regulate emotions; higher arousal led to an inability to attack aliens. When paired with therapist-administered CBT, those treated had better anger and emotional control than TAU.

In addition to anxiety and anger, many TGs target general life stress. Using CBT, "Dealing with Others," when combined with therapy, was found to improve coping skills for burnout syndrome more than therapy alone. ${ }^{66}$ "Dealing with Others" trains individuals to assertively communicate with coworkers and offers positive thoughts about themselves or society. Difficulty levels increase as players gather points.

Another CBT game, "Coping Coach," is a web-based game for children to prevent posttraumatic stress disorder (PTSD) after a medical event. ${ }^{67,68}$ "Coping Coach" directs children to create faces to match their feelings, to help game characters learn cognitive restructuring, and to understand why characters avoid situations. While effect sizes indicate the potential to reduce post-traumatic symptomology, there were no significant differences between the treatment and a wait-list control. $^{67}$

Attention deficit and hyperactivity disorder. "Journey of the Wild Divine" has also been evaluated with children diagnosed with ADHD. ${ }^{50}$ The experimental group had reductions in ADHD behaviors. The game uses imagery and music based on biofeedback. Goals are accomplished if breathing is slow and deep. For example, one may build a bridge, which will disappear if breathing becomes too fast and reappear 
when slow again. Most ADHD TGs target CR, particularly executive functioning, and are reviewed elsewhere. ${ }^{69}$

\section{Guidelines for therapeutic game development}

Before embarking on TG development, one must account for three key issues. First, game designers need to possess a good understanding of the disorder, theoretical underpinnings of the intervention, and VGs. ${ }^{24}$ Second, the cost is frequently substantial, with the cheapest reviewed game costing around $\$ 25,000$ to develop. ${ }^{22}$ Other reviews provide more technical information on developing games. ${ }^{70,71}$ Third, the technology platform (computer, smartphone, tablet, RGB-D) can make a substantial difference in treatment outcomes as seen in one emotion regulation study. ${ }^{72}$ In addition to these basic requirements, we consolidated a set of guidelines enumerated by researchers and reviewers as best practices of their experiences (refer to Table 2).

Table 2. Guidelines for Developing Digital Mental HEALTH INTERVENTIONS

\section{Engagement}

(1) Characters and gameplay should relate to the patient. ${ }^{24,27}$

(2) Gameplay must be motivating, interesting, and engaging. $5,7,24,84,85$

(3) Length of gameplay must be not too long or short. ${ }^{8}$

(4) Game must have immediate feedback. ${ }^{5}$

(5) Game must be easy to play. ${ }^{27}$

(6) Game should have a large base of novel stimuli or situations. $^{27}$

(7) Use social media to improve motivation. ${ }^{27}$

Accessibility

(8) Game must be easily accessible. $5,27,30,31$

(9) The game must work in the treatment

environment. ${ }^{22,24}$

(10) Game is more effective if accessible by phone. ${ }^{30}$

Consistency with treatment

(11) Develop with your patient in mind. ${ }^{24,25}$

(12) Game design and play should be conceptually sound, in terms of best practices for both therapy and training. ${ }^{24}$

(13) Game must have clearly defined and implemented learning goals. $^{24,60}$

Generalizability

(14) Game must conform to a high degree of realism and immersion. ${ }^{5,24}$

(15) Too much or too little input of the player can affect the usefulness of the intervention. ${ }^{8}$

(16) Game content has real-world problems. ${ }^{23,27}$

Effective skill building

(17) In order for true skill development to occur, a gamebased environment must have the learner work through the three stages of skill acquisition: cognitive, associative, and autonomous. ${ }^{24}$

(18) Gameplay must be frequent yet not excessive. ${ }^{24,27}$

(19) Game has difficulty level that adjusts to the player. ${ }^{5}$ (20) Game must be interactive with moderate task demand. 7,84

General advice for developers

(21) Plan for the cost of creating game, which can be as low as $\$ 25,000$. $^{22}$

(22) Game designers should be well versed in subject matter and videogames. ${ }^{24}$
Games are useful supplements to therapy ${ }^{73}$ as their activities may be more motivating for clients than traditional therapy. ${ }^{31}$ Well-designed TGs are based on the same principles as therapy, but also provide convenient and engaging treatment access, as seen with "Coping Coach."74 The most common recommendations for increasing the frequency of supplemental practice involve games being convenient, accessible, engaging, and soundly based. ${ }^{5,24,25,27}$ Games should be relatable to the individual, be immersive to accurately represent real-world challenges, and be able to scaffold ability by progressing through stages of skill development. $5,23,24,27$

Engagement. People play games for competition, challenge, social interaction, diversion, fantasy, and arousal. ${ }^{75}$ TGs using these criteria can successfully engage clients in skill practice. Games incorporate many strategies to enhance engagement, including immersive characters and stories (e.g., "Reach Out Central"), immediate goals such as level completion (e.g., "SPARX"), and points for successful activities (e.g., "Personal Zen"). $25,27,56$

Accessibility. Another key characteristic of TGs is increased accessibility to users. ${ }^{5,27,31}$ The primary purpose of TGs is to practice skills without the presence of a therapist. Expensive, inaccessible games would not be nearly as effective in encouraging continued use as affordable, portable games.

Accessibility may actively encourage use through explicit reminders such as app-based push notifications or by more frequent encounters. Therefore, researchers ${ }^{56,58}$ may favor web-based games or smartphone applications, especially with the rise of smartphone users. ${ }^{76}$ For example, "Virtual Hope Box," a smartphone app with individualized coping tools, including casual games, was used more frequently than a conventional hope box method by patients at risk of suicide and self-harm. ${ }^{77}$ In fact, the Veterans' Administration is introducing mobile mental health interventions to improve accessibility to the military. ${ }^{78}$ Promising new studies indicate the potential for biofeedback to occur via mobile devices. ${ }^{59,79}$

Consistency with treatment. In addition, TGs must be founded on evidence-supported treatments. For example, the reviewed TGs are based on biofeedback, CBT, and stimulus

Table 3. Promising Intervention Games Not Yet EMPIRICALly TESTED

\begin{tabular}{ll}
\hline Game & \multicolumn{1}{c}{ Target problem } \\
\hline "Ricky the Spider",86 & $\begin{array}{l}\text { Pediatric obsessive } \\
\text { compulsive disorder } \\
\text { Mental disorders }\end{array}$ \\
"Treasure Hunt,"22 & Depression \\
"Depression Quest",87 & Depression \\
"The Cat Lady"88 & Anxiety/stress \\
"Headspace"89 & Depression \\
"gNats Island"90 & Depression \\
"Maya"91 & Post-traumatic stress disorder \\
"Walk in My Shoes"92 & Distress \\
"Personal Investigator",93 & Psychosis recovery \\
"Pogo's Pledge",94 & ADHD \\
"Plan It Commander",95 & Emotion regulation \\
\hline
\end{tabular}


control, which could potentially complement ongoing psychotherapy. ${ }^{50}$ As in "MindLight," ${ }^{, 60}$ game designers must ensure that thought processes and behaviors stimulated by game play are compatible with therapy goals.

Generalizability. Beyond matching treatment rationale, games should also translate to real-world situations. A game that is highly realistic is likely to inspire high levels of immersion and cognitive states associated with emotions of virtual task. ${ }^{80}$

Game designers have also noted the importance of realism to increase transfer-of-training to real-world scenarios. For example, the designers of "Guardian Angel" purposefully created characters that "almost identically" represented the clients for whom the game was designed. ${ }^{24}$ They further note that the game should account for the client's characteristics, as players may have different motivations, reading levels, and motor control. Game and scenario types may affect certain populations differently (e.g., females improving more in "Reach Out Central" ${ }^{27}$ ). Another key for immersion is to incorporate real-world problems. ${ }^{23,27}$ As such, VR games are likely to be generalizable.

Effective skill building. TGs should promote successful skill building through practice to increase skill longevity. This involves creating a game that stays within players' "zone of proximal development" through moderate task demand ${ }^{8}$ or through game difficulty levels adjusted to individual players. ${ }^{5}$ Bowers et al. ${ }^{24}$ consider three different phases of learning as players proceduralize game techniques: cognitive, associative, and autonomous. Guiding players to generate automatic responses is integral to personal growth.

Aside from skill building, task demand affects how people choose what game to play, ${ }^{8}$ with moderate task demand increasing game play. In turn, increased game play likely leads to greater practice and gains. Moderate task demand also likely facilitates automatization of skills that, before play, are somewhat effortful and controlled. ${ }^{8}$

Time and cost. Based on our own experience and that of others, ${ }^{81}$ VG development may take 3 years, which may not include beta testing of the game. Game cost can vary based on complexity and graphic detail, with Baranowski and colleagues estimating millions of dollars for a high-end product. The challenge of TG development in academic settings includes gaining initial development funding and subsequent funding for evaluating efficacy. Unfortunately, research funding first requires feasibility data.

This lengthy research process becomes an impediment to technology-based research. The discrepancy between rapid technological change and the time needed to develop and evaluate TGs results in developers releasing games to the public before formal empirical testing (e.g., "Ricky the Spider" for pediatric obsessive compulsive disorder $[\mathrm{OCD}]^{22}$ ). This seems to be a trend mirrored with behavioral health mobile apps. ${ }^{82}$

Potential limitations for TGs. While research suggests the benefits of integrating TGs into clinical practice, some potential limitations exist. TGs may require an investment of time for the participants. Clinicians should consider diagnosis severity and social support availability when using TGs. For example, those with depression should be monitored and a clinician closely involved to mitigate risk of suicide or self-harm. Currently, TGs do not have empirical support as stand-alone treatments for any mental health condition. Guidelines should be established on which games require the presence of a therapist, especially for biofeedback and neurofeedback games.

\section{Conclusion}

Many TGs are based on a limited number of psychological interventions (e.g., biofeedback, CBT) for a limited range of mental disorders. However, future games could be based on other psychotherapies such as exposure, acceptance and commitment therapy, or mindfulness and for other mental disorders. Several promising TGs are yet to be evaluated empirically for emotion management (Table 3). Future studies should include more diverse samples as many of the reviewed studies $(n=14)$ evaluated adolescents and children. Game design can be adjusted for older demographics. ${ }^{83}$ Few empirically validated TGs exist for mental disorders. The guidelines summarized through our review may simplify and strengthen future TG creation. Using TGs as treatments or treatment adjuncts may increase options for clients, decrease barriers to care, and overcome stigma.

\section{Author Disclosure Statement}

No competing financial interests exist.

\section{References}

1. Connolly TM, Boyle EA, Macarthur E, et al. A systematic literature review of empirical evidence on computer games and serious games. Comput Educ 2012; 59:661-686.

2. Entertainment Software Association. Essential Facts About the Computer and Video Game Industry. 2015. www.theesa .com/wp-content/uploads/2015/04/ESA-Essential-Facts2015.pdf (accessed March 21, 2018).

3. Whitbourne SK, Ellenberg S, Akimoto K. Reasons for playing casual video games and perceived benefits among adults 18 to 80 years old. Cyberpsychol Behav Soc Netw 2013; 16:892-897.

4. Boyle E, Connolly TM, Hainey T. The role of psychology in understanding the impact of computer games. Entertain Comput 2011; 2:69-74.

5. Granic I, Lobel A, Engels RCME. The benefits of playing video games. Am Psychol 2014; 69:66-78.

6. Kharrazi H, Lu AS, Gharghabi F, Coleman W. A scoping review of health game research: Past, present, and future. Games Heal Res Dev Clin Appl 2012; 1:153-164.

7. Bowman ND, Tamborini R. "In the mood to game": Selective exposure and mood management processes in computer game play. New Media Soc 2015; 17:375-393.

8. Bowman ND, Tamborini R. Task demand and mood repair: The intervention potential of computer games. New Media Soc 2012; 14:1339-1357.

9. James EL, Bonsall MB, Hoppitt L, et al. Computer game play reduces intrusive memories of experimental trauma via reconsolidation-update mechanisms. Psychol Sci 2015; 26:1201-1215.

10. Holmes EA, James EL, Kilford EJ, Deeprose C. Key steps in developing a cognitive vaccine against traumatic flashbacks: Visuospatial Tetris versus verbal pub quiz. PLoS One 2010; 5:e13706. DOI: 10.1371/journal.pone.0013706.

11. Aventin Á, Houston S, Macdonald G. Utilising a computer game as a therapeutic intervention for youth in residential 
care: Some preliminary findings on use and acceptability. Child Youth Serv Rev 2014; 47(P3):362-369.

12. Bouchard S, Bernier F, Boivin É, et al. Using biofeedback while immersed in a stressful videogame increases the effectiveness of stress management skills in soldiers. PLoS One 2012; 7:e36169. DOI: 10.1371/journal.pone.0036169.

13. Russell WD, Newton M. Short-term psychological effects of interactive video game technology exercise on mood and attention. Educ Technol Soc 2008; 11:294-308.

14. Rosenberg D, Depp CA, Vahia IV, et al. Exergames for subsyndromal depression in older adults: A pilot study of a novel intervention. Am J Geriatr Psychiatry 2010; 18:221226.

15. Tsimaras V, Papaioannou M, Proios M, et al. The effect of a digital interactive game in distractibility, hyperactivity and impulsivity in individuals with attention deficit hyperactivity disorder and intellectual disability. J Phys Educ Sport 2014; 14:500-506.

16. Dupuis EC, Ramsey MA. The relation of social support to depression in massively multiplayer online role-playing games. J Appl Soc Psychol 2011; 41:2479-2491.

17. Collins E, Cox AL. Switch on to games: Can digital games aid post-work recovery? Int J Hum Comput Stud 2014; 72: 654-662.

18. Longman H, O'Connor E, Obst P. The effect of social support derived from World of Warcraft on negative psychological symptoms. Cyberpsychol Behav 2009; 12:563566.

19. Fish M, Russiello C, O'Brien K. The efficacy of prescribed casual videogame play in reducing symptoms of anxiety: A randomized controlled study. Games Heal J Res Dev Clin Appl 2014; 3:291-295.

20. Russoniello CV, O'Brien K, Parks JM. The effectiveness of casual video games in improving mood and decreasing stress. J Cyber Ther Rehabil 2009; 2:53-66.

21. Gamberini L, Barresi G, Majer A, Scarpetta F. A game a day keeps the doctor away: A short review of computer games in mental healthcare. J Cyber Ther Rehabil 2008; 1: 127-145.

22. Brezinka V. Computer games supporting cognitive behaviour therapy in children. Clin Child Psychol Psychiatry 2014; 19:100-110.

23. Knox M, Lentini J, Cummings TS, et al. Game-based biofeedback for paediatric anxiety and depression. Ment Health Fam Med 2011; 8:195-203.

24. Bowers C, Procci K, Joyce R, et al. Serious games for therapy: A training perspective. J Cyber Ther Rehabil 2011; 4:447-453.

25. Fernández-Aranda F, Jiménez-Murcia S, Santamaría JJ, et al. Video games as a complementary therapy tool in mental disorders: PlayMancer, a European multicentre study. J Ment Heal 2012; 21:364-374.

26. Li WH, Chung JO, Ho EK. The effectiveness of therapeutic play, using virtual reality computer games, in promoting the psychological well-being of children hospitalised with cancer. J Clin Nurs 2011; 20:2135-2143.

27. Shandley K, Austin D, Klein B, Kyrios M. An evaluation of "Reach Out Central": An online gaming program for supporting the mental health of young people. Health Educ Res 2010; 25:563-574.

28. Tanaka JW, Wolf JM, Klaiman C, et al. Using computerized games to teach face recognition skills to children with autism spectrum disorder: The Let's Face It! Program. J Child Psychol Psychiatry 2010; 51:944-952.
29. Walshe D, Lewis EJ, Kim SI, et al. Exploring the use of computer games and Virtual Reality in exposure therapy for fear of driving following a motor vehicle accident. Cyberpsychol Behav 2003; 6:329-334.

30. Pallavicini F, Algeri D, Repetto C, et al. Biofeedback, virtual reality and mobile phones in the treatment of generalized anxiety disorder (GAD): A phase- 2 controlled clinical trial. J Cyber Ther Rehabil 2009; 2:315-327.

31. Ceranoglu TA. Video games in psychotherapy. Rev Gen Psychol 2010; 14:141-146.

32. Li J, Theng Y-L, Foo S. Effect of exergames on depression: A systematic review and meta-analysis. Cyberpsychol Behav Soc Netw 2016; 19:34-42.

33. Malbos E, Rapee RM, Kavakli M. Creation of interactive virtual environments for exposure therapy through gamelevel editors: Comparison and tests on presence and anxiety. Int J Hum Comput Interact 2013; 29:827-837.

34. Beaumont R, Sofronoff K. A multi-component social skills intervention for children with Asperger syndrome: The junior detective training program. J Child Psychol Psychiatry 2008; 49:743-753.

35. Silver M, Oakes P. Evaluation of a new computer intervention to teach people with autism or Asperger syndrome to recognize and predict emotions in others. Autism 2001; 5:299-316.

36. Malinverni L, Mora-Guiard J, Padillo V, et al. An inclusive design approach for developing video games for children with autism spectrum disorder. Comput Human Behav 2017; 71:535-549.

37. Whyte EM, Smyth JM, Scherf KS. Designing serious game interventions for individuals with autism. J Autism Dev Disord 2015; 45:3820-3831.

38. Amado I, Brénugat-Herné L, Orriols E, et al. A serious game to improve cognitive functions in schizophrenia: A pilot study. Front Psychiatry 2016; 7:1-11.

39. Anguera JA, Gunning FM, Areán PA. Improving late life depression and cognitive control through the use of therapeutic video game technology: A proof-of-concept randomized trial. Depress Anxiety 2017; 34:508-517.

40. Opriş D, Pintea S, García-Palacios A, et al. Virtual reality exposure therapy in anxiety disorders: A quantitative metaanalysis. Depress Anxiety 2012; 29:85-93.

41. Parsons TD, Rizzo AA. Affective outcomes of virtual reality exposure therapy for anxiety and specific phobias: A meta-analysis. J Behav Ther Exp Psychiatry 2008; 39:250261.

42. Stallard P, Richardson T, Velleman S, Attwood M. Computerized CBT (think, feel, do) for depression and anxiety in children and adolescents: Outcomes and feedback from a pilot randomized controlled trial. Behav Cogn Psychother 2011; 39:273-284.

43. Fleming T, Cheek C, Merry SN, et al. Serious games for the treatment or prevention of depression: A systematic review. Rev Psicopatol Psicol Clín 2014; 19:227-242.

44. Li J, Theng Y-L, Foo S. Game-based digital interventions for depression therapy: A systematic review and metaanalysis. Cyberpsychol Behav Soc Netw 2014; 17:519527.

45. Lucassen MFG, Merry SN, Hatcher S, Frampton CMA. Rainbow SPARX: A novel approach to addressing depression in sexual minority youth. Cogn Behav Pract 2015; 22:203-216.

46. Merry SN, Stasiak K, Shepherd M, et al. The effectiveness of SPARX, a computerised self help intervention for ado- 
lescents seeking help for depression: Randomised controlled non-inferiority trial. BMJ 2012; 344:e2598.

47. Poppelaars M, Tak YR, Lichtwarck-Aschoff A, et al. A randomized controlled trial comparing two cognitivebehavioral programs for adolescent girls with subclinical depression: A school-based program (Op Volle Kracht) and a computerized program (SPARX). Behav Res Ther 2016; $80: 33-42$.

48. Fleming T, Dixon R, Frampton C, Merry S. A pragmatic randomized controlled trial of computerized CBT (SPARX) for symptoms of depression among adolescents excluded from mainstream education. Behav Cogn Psychother 2012; 40:529-541.

49. Stasiak K, Hatcher S, Frampton C, et al. A pilot double blind randomized placebo controlled trial of a prototype computer-based cognitive behavioural therapy program for adolescents with symptoms of depression. Behav Cogn Psychother 2014; 42:385-401.

50. Amon KL, Campbell A. Can children with AD/HD learn relaxation and breathing techniques through biofeedback video games? Aust J Educ Dev Psychol 2008; 8:72-84.

51. Verduin ML, Larowe SD, Myrick H, et al. Computer simulation games as an adjunct for treatment in male veterans with alcohol use disorder. J Subst Abuse Treat 2011; 44:316-322.

52. Fernández-Aranda F, Jimenez-Murcia S, Santamaría JJ, et al. The use of videogames as complementary therapeutic tool for cognitive behavioral therapy in bulimia nervosa patients. Cyberpsychol Behav Soc Netw 2015; 18:1-7.

53. Fagundo AB, Santamaría JJ, Forcano L, et al. Video game therapy for emotional regulation and impulsivity control in a series of treated cases with bulimia nervosa. Eur Eat Disord Rev 2013; 21:493-499.

54. Tárrega S, Castro-Carreras L, Fernández-Aranda F, et al. A serious videogame as an additional therapy tool for training emotional regulation and impulsivity control in severe gambling disorder. Front Psychol 2015; 6:1-12.

55. Reinecke L. Games and recovery: The use of video and computer games to recuperate from stress and strain. J Media Psychol 2009; 21:126-142.

56. Dennis-Tiwary TA, O'Toole LJ. Mental health on the go: Effects of a gamified attention-bias modification mobile application in trait-anxious adults. Clin Psychol Sci 2014; 2:576-590.

57. Dennis-Tiwary TA, Egan LJ, Babkirk S, Denefrio S. For whom the bell tolls: Neurocognitive individual differences in the acute stress-reduction effects of an attention bias modification game for anxiety. Behav Res Ther 2016; 77: 105-117.

58. Pham Q, Khatib Y, Stansfeld S, et al. Feasibility and efficacy of an mHealth game for managing anxiety: A randomized controlled trial. Games Health J 2016; 5:50-67.

59. Dillon A, Kelly M, Robertson IH, Robertson DA. Smartphone applications utilizing biofeedback can aid stress reduction. Front Psychol 2016; 7:832. DOI: 10.3389/fpsyg .2016.00832.

60. Schoneveld EA, Malmberg M, Lichtwarck-Aschoff A, et al. A neurofeedback video game (MindLight) to prevent anxiety in children: A randomized controlled trial. Comput Human Behav 2016; 63:321-333.

61. Yahav R, Cohen M. Evaluation of a cognitive-behavioral intervention for adolescents. Int J Stress Manag 2008; 15 : 173-188.
62. Scholten H, Malmberg M, Lobel A, et al. A randomized controlled trial to test the effectiveness of an immersive 3D video game for anxiety prevention among adolescents. PLoS One 2016; 11:1-25.

63. Schuurmans AAT, Nijhof KS, Vermaes IPR, et al. A pilot study evaluating "Dojo," a videogame intervention for youths with externalizing and anxiety problems. Games Heal 2015; 4:401-408.

64. Khanna MS, Kendall PC. Computer-assisted cognitive behavioral therapy for child anxiety: Results of a randomized clinical trial. J Consult Clin Psychol 2010; 78:737-745.

65. Kahn J, Ducharme P, Rotenberg A, Gonzalez-Heydrich J. "RAGE-Control": A game to build emotional strength. Games Health J 2013; 2:53-57.

66. Zielhorst T, Van Den Brule D, Visch V, et al. Using a digital game for training desirable behavior in cognitivebehavioral therapy of burnout syndrome: A controlled study. Cyberpsychol Behav Soc Netw 2015; 18:101-112.

67. Kassam-Adams N, Marsac ML, Kohser KL, et al. Pilot randomized controlled trial of a novel web-based intervention to prevent posttraumatic stress in children following medical events. J Pediatr Psychol 2016; 41:138-148.

68. Marsac ML, Kohser KL, Winston FK, et al. Using a webbased game to prevent posttraumatic stress in children following medical events: Design of a randomized controlled trial. Eur J Psychotraumatol 2013; 4:1-9. DOI: 10.3402/ejpt.v4i0.21311.

69. Rivero TS, Nuñez LMH, Pires EU, Bueno OFA. ADHD rehabilitation through video gaming: A systematic review using PRISMA guidelines of the current findings and the associated risk of bias. Front Psychiatry 2015; 6:1-16. DOI: 10.3389/fpsyt.2015.00151.

70. Turner WA, Thomas B, Casey LM. Developing games for mental health: A primer. Prof Psychol Res Pract 2016; 47: 242-249.

71. Hayes ER, Games IA. Making computer games and design thinking. Games Cult 2008; 3:309-332.

72. Vara DM, Banos RM, Rasal P, et al. A game for emotional regulation in adolescents: The (body) interface device matters. Computers 2016; 57:267-273.

73. Santamaria JJ, Soto A, Fernandez-Aranda F, et al. Serious games as additional psychological support: A review of the literature. J Cyber Ther Rehabil 2011; 4:469-476.

74. Marsac ML, Winston FK, Hildenbrand AK, et al. Systematic, theoretically-grounded development and feasibility testing of an innovative, preventive web-based game for children exposed to acute trauma. Clin Pract Pediatr Psychol 2015; 3:12-24.

75. Lucas K, Sherry JL. Sex differences in video game play. Commun Res 2004; 31:499-523.

76. Kim H-M. Mobile media technology and popular mobile games in contemporary society. Int J Mob Mark 2013; 8:42-54.

77. Bush NE, Dobscha SK, Crumpton R, et al. A virtual hope box smartphone app as an accessory to therapy: Proof-ofconcept in a clinical sample of veterans. Suicide Life Threat Behav 2015; 45:1-9.

78. Shore JH, Aldag M, McVeigh FL, et al. Review of mobile health technology for military mental health. Mil Med 2014; 179:865-878.

79. Chittaro L, Sioni R. Affective computing vs. affective placebo: Study of a biofeedback-controlled game for relaxation training. Int J Hum Comput Stud 2014; 72:663673. 
80. McGloin R, Farrar K, Krcmar M. Video games, immersion, and cognitive aggression: Does the controller matter? Media Psychol 2013; 16:65-87.

81. Baranowksi T, Buday R, Thompson DI, Baranowski J. Video games and stories for health-related behavior change. Am J Prev Med 2008; 34:74-82.

82. Wiederhold BK. Behavioral health apps abundant, but evidence-based research nearly nonexistent. Cyberpsychol Behav Soc Netw 2015; 18:309-310.

83. Brown JA, De Schutter B. Game design for older adults: Lessons from a life course perspective. Int J Gaming Comput Simulations 2016; 8:1-12.

84. Rieger D, Frischlich L, Wulf T, et al. Eating ghosts: The underlying mechanisms of mood repair via interactive and noninteractive media. Psychol Pop Media Cult 2015; 4:138-154.

85. Rieger D, Wulf T, Kneer J, et al. The winner takes it all: The effect of in-game success and need satisfaction on mood repair and enjoyment. Comput Human Behav 2014; 39:281-286.

86. Brezinka V. Ricky and the Spider-A video game to support cognitive behavioural treatment of children with obsessivecompulsive disorder. Clin Neuropsychiatry J Treat Eval 2013; 10(Suppl 1):6-12.

87. Quinn Z. Depression Quest. 2013. www.depressionquest .com (accessed March 21, 2018).

88. Robbins MB. Depression \& gaming. Libr J 2014; 139:62.

89. Laurie J, Blandford A. Making time for mindfulness. Int J Med Inform 2016; 96:38-50.

90. Coyle D, McGlade N, Doherty G, O’Reilly G. Exploratory evaluations of a computer game supporting cognitive behavioural therapy for adolescents. ACM CHI Conference, 2011; 2937-2946. DOI: 10.1145/1978942.1979378.
91. Carrasco A. Acceptability of an adventure video game in the treatment of female adolescents with symptoms of depression. Res Psychother Psychopathol Process Outcome 2016; 19:10-18.

92. Kreutzer CP, Bowers CA. Attitudes toward a game-based approach to mental health. Cyberpsychol Behav Soc Netw 2015; 18:20-24.

93. Coyle D, Doherty G, Sharry J. An evaluation of a solution focused computer game in adolescent interventions. Clin Child Psychol Psychiatry 2009; 14:345-360.

94. Shrimpton B, Hurworth R. Adventures in evaluation: Reviewing a CD-ROM based adventure game designed for young people recovering from psychosis. J Educ Multimed Hypermedia 2005; 14:273-290.

95. Bul KCM, Franken IHA, Van der Oord S, et al. Development and user satisfaction of "plan-it commander," a serious game for children with ADHD. Games Health J 2015; 4:502-512.

96. Crystals of Kaydor. http://learninggamesnetwork.org/ microsites/kaydor/ (accessed January 29, 2018).

Address correspondence to: Avani Shah, PhD, MSW School of Social Work University of Alabama Little Hall 670 Judy Bonner Drive Tuscaloosa, AL 35401

E-mail:shah009@sw.ua.edu 